\title{
Philippe Berthier, Stendhal. Vivre, Écrire, Aimer
}

\section{Michel Arrous}

\section{(2) OpenEdition}

\section{Journals}

\section{Édition électronique}

URL : http://journals.openedition.org/studifrancesi/5660

DOI : 10.4000/studifrancesi.5660

ISSN : 2427-5856

\section{Éditeur}

Rosenberg \& Sellier

\section{Édition imprimée}

Date de publication : 1 septembre 2011

Pagination : 422

ISSN : 0039-2944

\section{Référence électronique}

Michel Arrous, «Philippe Berthier, Stendhal. Vivre, Écrire, Aimer», Studi Francesi [En ligne], 164 (LV | II) |

2011, mis en ligne le 30 novembre 2015, consulté le 08 janvier 2021. URL : http://

journals.openedition.org/studifrancesi/5660; DOI : https://doi.org/10.4000/studifrancesi.5660

Ce document a été généré automatiquement le 8 janvier 2021.

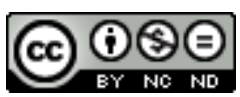

Studi Francesi è distribuita con Licenza Creative Commons Attribuzione - Non commerciale - Non opere derivate 4.0 Internazionale. 


\title{
Philippe Berthier, Stendhal. Vivre, Écrire, Aimer
}

\author{
Michel Arrous
}

\section{RÉFÉRENCE}

PHILIPPE BERTHIER, Stendhal. Vivre, Écrire, Aimer, Paris, Éditions de Fallois, 2010, 542 pp.

Bien que la biographie soit un genre réputé suspect, il arrive que la compréhension sympathique doublée d'une sûre érudition rende possible la connaissance d'un individu à travers sa trajectoire existentielle. Dans le cas de Stendhal, qui a déjà raconté sa vie et qui ne tenait guère à ce qu'on connaisse autre chose de lui que ce qu'il avait écrit, on peut juger que la tâche a été amplement accomplie par Henri Martineau (Le Cour de Stendhal, 1952-1953) et, évidemment, par Michel Crouzet (Stendhal ou monsieur moimême, 1990, rééd. 1999), d'autant plus que, durant ces vingt dernières années, le regard sur l'écrivain n'a pas radicalement changé et qu'aucun document important n'a été publié. On ne trouvera donc dans cette biographie aucune révélation, mais Philippe Berthier a su dire les mêmes choses autrement et avec brio, sur un ton parfois ironique mais jamais désinvolte. Aussi tout l'intérêt du livre, qui n'a sans doute pas été écrit pour les seuls stendhaliens, réside-t-il dans la manière de raconter les faits. Tout d'abord, et c'est plus qu'une habile originalité, le récit linéaire, de la préhistoire de la famille Beyle aux débuts du stendhalisme, est placé dès les premières pages et par la grâce des épigraphes sous le double signe de l'Italie et de la musique, voire saturé de mentions ou d'allusions à cette passion essentielle que fut l'opéra, jusqu'à Verdi ou Puccini que notre «lyricomaniaque» n'a bien sûr pu connaître, mais dont les thèmes ou la résonance sont stendhaliens. La seconde, plaisamment anachronique mais qui n'a rien non plus d'un caprice, réside dans le parti pris de convoquer les modernes pour donner à la plupart des chapitres un titre immédiatement évocateur. À cela s'ajoutent, comme autant d'intrusions d'auteur, d'heureuses formules et d'amusantes familiarités - Giulia et son "pot à tabac quadragénaire», possible mari et éventuel papa: «oui, le beyliste a envisagé cette incroyable possibilité: être père de famille»! - qui 
scandent le récit: on souffre avec «Henri le rétif» qui affronte précepteurs et magisters, on suit ses premiers pas dans le monde et on comprend son marasme et son fiasco devant Daru la Terreur, mais une fois sur les rivages heureux de l'Italie, «Henri libère l'Italie et se libère lui-même». On pourrait encore citer les pages sur le père affameur, sur Pauline, "partenaire d'élection et d'invention» dans une relation pédagogique fabriquée de toutes pièces, les amours avec Mélanie et tout l'épisode marseillais («La vie d'Henri est réglée comme du papier à musique, sans musique»), la question du plagiat et la «désinvolture de forban» qui caractérise le très fameux Bombet, l'évocation de la libido beyliste, dans le récit de l'amour pour Métilde comme dans celui de la mésaventure avec Alexandrine, ou la mention des tours de force vraiment olympiques avec Mme Galice (Citius, altius, fortius). On appréciera que dans le récit factuel s'insèrent des pauses consacrées aux œuvres dont l'essentiel est dit. Bien sûr, des énigmes subsistent qui attendent quelque stendhalien fureteur; il se pourrait aussi que certains, sans pour autant parler de déficience historique, jugent l'arrière-plan insuffisamment évoqué. Ce qui emporte l'adhésion du lecteur, c'est la subtile empathie d'un biographe à l'unisson avec la sensibilité de Stendhal. Plutôt qu'au personnage dans son temps, Philippe Berthier s'est attaché à donner de Stendhal un portrait intime. 